\title{
Applicability of finger jointing to circular laminated veneer hollow sections for temporary soil nailing
}

\author{
Sebastian Hirschmüller ${ }^{1}$ (D) $\cdot$ Roman Marte $^{2} \cdot$ Alexander Englberger $^{1}$
}

Received: 16 September 2019 / Published online: 6 August 2020

(c) The Author(s) 2020

\begin{abstract}
This paper investigates the strength properties of circular laminated veneer lumber hollow sections made of beech wood and loaded in tension. These tubular, hollow wooden poles are intended for an innovative geotechnical approach, which utilizes the high tensile strength of beech wood and its limited durability as soil nails for temporary geotechnical slope stabilisation. Due to the standardized design approaches of soil nail walls that prevent a rigid soil body from sliding by using nails as reinforcement elements, primary tension loads will be aligned to the structural elements. Depending on the height of the soil nail wall, nails with a length up to $10 \mathrm{~m}$ may be necessary, demanding for high-performance longitudinal section joints due to the natural length limitations of the wood veneer. This paper discusses the applicability of finger jointing to tubular, laminated beech wood veneer poles and presents the results of large-scale tensile tests. Depending on the joint arrangement, the median tensile strength is reduced by $37-43 \%$ compared to the unjointed sections of a similar geometry. Thus, finger jointing has been found to be an efficient method of a longitudinal load-carrying connection in combination with a minimized cross section reduction at the joint. However, due to the low sample size of the tests, further improvements are necessary.
\end{abstract}

\section{Introduction}

\subsection{Geotechnical background}

Currently, soil nailing is a common way of slope stabilization in foundation engineering. Therefore, steel anchors are drilled into the soil and a reinforced shotcrete layer protects the slope surface. The gap around the steel rod is filled with cement grout. The hardened cement body ensures the necessary connection (force closure) between soil and anchor. For the temporary stabilisation of construction pit slopes, soil nailing systems are usually used. In case of temporary soil nailing systems, the construction has a reduced service

Sebastian Hirschmüller

sebastian.hirschmueller@th-rosenheim.de

Roman Marte

roman.marte@tugraz.at

Alexander Englberger

alexander.englberger@th-rosenheim.de

1 Department of Research and Development, University of Applied Sciences Rosenheim, Rosenheim, Germany

2 Institute of Soil Mechanics, Foundation Engineering and Computational Geotechnics, Graz University of Technology, Graz, Austria life of 2 years maximum. Thereafter, the anchors have no structural use, but usually remain in the soil, because it is generally not possible to remove them due to their limited accessibility after installation. The objective of this research topic is to replace the temporary steel nails in cut slopes reinforced with circular laminated hollow sections CLHS (Fig. 1) from European beech (Fagus sylvatica L.).

The motivation is to develop a sustainable soil nailing system for temporary purposes in combination with a new way of using beech wood by combining both positive and negative beech material properties (i.e., high strength and low durability). The wooden soil reinforcement elements decompose in the soil after fulfilling their expected service life. Figure 2a shows a typical slope excavation supported by a shotcrete layer and steel nails, and Fig. 2 b illustrates the method using wood-based reinforcement elements.

Since the construction of the first reinforced soil walls, first design approaches were developed based on the results of large-scale field tests (Gäßler and Gudehus 1981; Gäßler 1987; Project National Clouterre 1991). Generally, the reinforced soil in combination with the soil facing is assumed to form a composite body, resisting external-acting lateral and vertical forces. To ensure the internal bearing capacity of the reinforced soil body (internal stability), besides numerical methods, various other design concepts were 


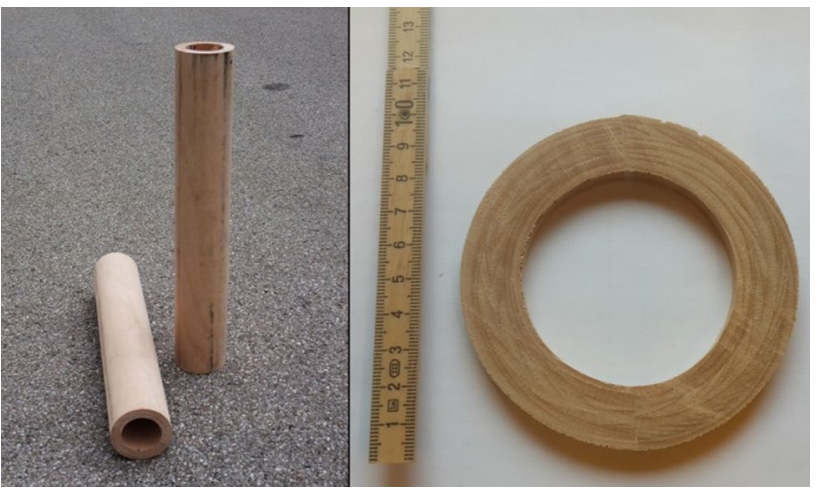

Fig. 1 CLHS prototypes (left) made of beech wood and related cross section with $100 \mathrm{~mm}$ outer diameter and $18 \mathrm{~mm}$ wall thickness (right)

developed based on mechanical limit equilibrium considerations of rigid body motions. Existing slope stability analysis methods, where external forces act on the rigid body, are compared to mobilised resistances in the soil and extended by reinforcement elements. Thus, based on current state of the art design methods, only tensile forces are considered as forces acting in the reinforcement elements.

Bar-shaped elements for load-bearing timber structures are usually made of solid wood or engineered wood products like glue laminated timber, cross laminated timber (CLT) or laminated veneer lumber (LVL). With regard to the material yield during production, processing issues as well as the structural design of constructions and connections, rectangular cross-section geometries are usually preferred for load-bearing timber elements. However, cement grouted soil nails act as a composite element similar to reinforcement bars in concrete structures due to the force transformation from the soil into the bar. Therefore, the nail's tensile capacity and bonding behaviour between the nail and the surrounding cement are essential and depend significantly on the available contact surface between the bar and the cement grout. Inspired by blades of grass, circular ring-shaped cross-sections offer high stability due to the optimised proportion between the second moment of area $\mathrm{I}_{\mathrm{Y}, \mathrm{Z}}$ and crosssection area $\mathrm{A}_{\mathrm{t}}$. Additionally, a circular cross-section of the reinforcement members offers an optimized ratio between outer periphery $\mathrm{U}_{\text {out }}$ and $\mathrm{A}_{\mathrm{t}}$ compared to rectangular geometries (Fig. 3) and is therefore preferably used for reinforcement elements primarily loaded in tension. Because of practical concerns, CLHS for soil nailing have to be installed by cased drillings. For technical reasons, an installation similar to a self-drilling anchor is not possible at the moment. The outer diameter $d_{t}$ of the CLHS is limited to about $100 \mathrm{~mm}$ due to a common bore hole diameter of about $140 \mathrm{~mm}$ and a minimum thickness of the surrounding cement body of $20 \mathrm{~mm}$. The wall thickness $t$ of the poles is given by the tensile force in the nail as well as the minimum possible curvature of the veneers in the inner diameter $d_{i}$ without destruction of the veneer perpendicular to the fiber direction. The thicker the wall the lower the radius of the innermost veneer of the hollow section. Peeling cracks and maximum

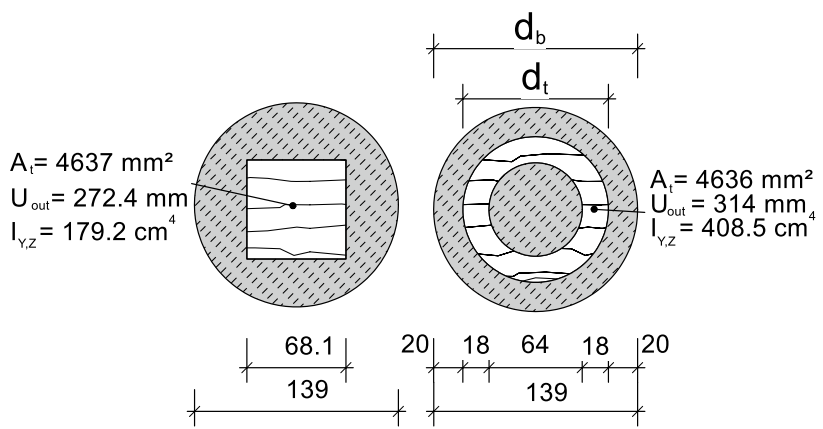

Fig. 3 Cross-section of a cement-grouted bore hole with rectangular reinforcement member (left) and a circular hollow section member (right); all dimensions in millimeters
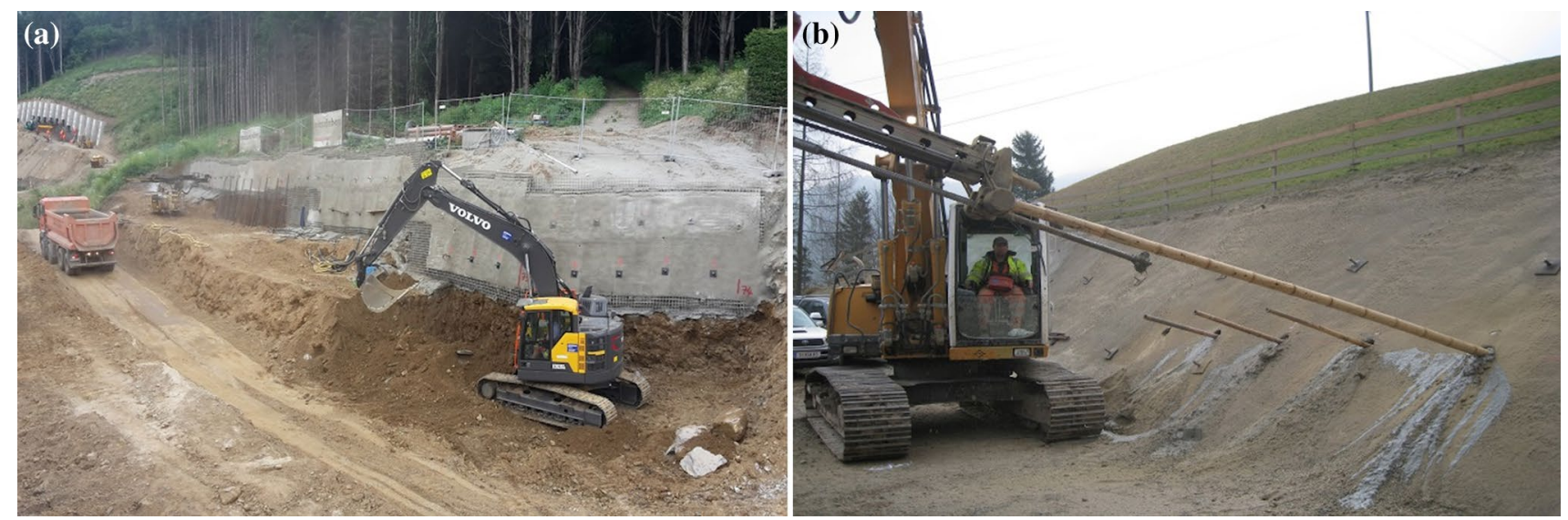

Fig. 2 a Standard soil nailing system; b slope stabilisation using hollow wooden sections 
applicable bending strains perpendicular to the grain limit the minimum radius of the inner veneers. A wall thickness of approximately $18 \mathrm{~mm}$ (6 layers of $3 \mathrm{~mm}$ thick veneers respectively) and an inner diameter $\mathrm{d}_{\mathrm{i}}$ of $64 \mathrm{~mm}$ were found to be suitable for the manufacturing process without crushing the innermost veneers and has been adopted for all investigations. The fiber direction of all veneer layers corresponds to the pole axis.

\subsection{Previous CLHS material property investigations}

CLHS tensile and bending properties and the influence of high moisture and alkaline attack were determined on small specimens, free from defects, as already described in Hirschmüller et al. (2016, 2018b) and Hirschmüller (2019). Thus, suitable wood material, which was free from defects, knotless and flawless was used for the production of the LVL samples. This part of the research work has primarily been done to investigate the influence of veneer thickness and curvature on LVL material properties and to define a proper CLHS layer structure. However, for the definition of design values, testing of structural-sized members is inevitable, as brittle material strength is strongly influenced by a volume size effect. This effect is mainly caused by a higher probability of strength-reducing wood defects appearing in a larger material volume. Current soil nailing design methods based on limit equilibrium considerations mainly align tensile forces with the nail, therefore the research focus was inter alia on the determination of tensile properties of CLHS in structural dimensions.

\subsection{Endless CLHS production processes}

Temporary soil nailing walls with a wall height $\mathrm{H}_{\mathrm{S}}$ up to about 6-7 m cover a large range of geometries commonly used in practice resulting in a nail length $\mathrm{L}_{\mathrm{N}}$ not exceeding $6 \mathrm{~m}$ (corresponding to a guide value of approximately $80 \%$ of the total soil nailing wall height $\mathrm{H}_{\mathrm{S}}$ ). Industrially produced rotary cut veneers are available in lengths up to $3 \mathrm{~m}$ and therefore, limit the length of available continuous CLHS without joints. Thus, reliable and efficient longitudinal CLHS jointing without a significant cross-section reduction is a crucial factor for CLHS production of the required lengths. Various concepts have been suggested in the literature to produce long CLHS sections. Hara et al. (1994) used long veneer strips, which were longitudinally connected by finger joints of the single veneers, for the production of moulded 1/6 round LVL. The moulded LVL were connected in a high frequency heating press, suggesting a continuous roll forming process (presented by Srinivasan et al. 2008 14 years later) for the production of long structural elements. Hata et al. (2001) proposed "spiral-winding" of veneer strips wrapped around a mandrel in an interlocking pattern for endless pole production. Gilbert et al. (2017) investigated three longitudinal jointing approaches of CLHS sections and compared the bending capacity, determined in four point bending tests, to similarly produced reference samples without joints. The authors varied the longitudinal joint by

- wrapping fiber-reinforced polymer around the longitudinal CLHS butt joint (94\% bending capacity)

- longitudinal staggering of butt-jointed veneers within the section in a similar process to that used to construct LVL products ( $83 \%$ bending capacity).

Nevertheless, all presented approaches for the production of longer veneer-based structural profiles are based on material jointing, either of veneers or of layered veneer members. However, finger jointing standardised in EN 15497 (2014), is a high-performance jointing method mainly used for the longitudinal connection of timber boards as basic material in glulam processing. Youngquist et al. (1984) applied finger jointing to softwood LVL products and found a competitive method of LVL end jointing. However, finger joints in the LVL resulted in fast dulling of the cutter head, especially if the finger joints were adjusted parallel to the adhesive plane with glue lines abrading the cutters at one location on the tool. Biblis and Carino (1993) confirmed the strength influence of finger joint orientation and proposed an orientation perpendicular to the adhesive plane to generate reliable connections. Although these publications indicate that finger jointing is a promising way for longitudinal softwood LVLconnection, several investigations report on a limited loading capacity of finger-jointed beech wood lamellas in glued laminated timber (Aicher 2001; Volkmer et al. 2017; Ehrhart et al. 2018). However, to the author's knowledge only limited information about end-jointing of structural hardwood LVL hollow sections using the finger jointing method is available. Thus, this paper discusses the applicability of finger jointing to beech wood laminated veneer lumber hollow sections and presents the results of large-scale tensile tests under variation of the joint arrangement.

\section{Materials and methods}

\subsection{CLHS manufacturing and sampling}

The tensile properties of full-sized CLHS with and without finger joints were determined in extensive test series of specimens conditioned in normal climate (NC) at $20{ }^{\circ} \mathrm{C}$ and $65 \%$ relative humidity $(\mathrm{RH})$ until reaching equilibrium moisture content $\mathrm{u}_{\mathrm{gl}}\left(\mathrm{u}_{\mathrm{gl}} \approx 11.3 \%\right)$. The $2450 \mathrm{~mm}$ long CLHS specimens were made of four layers $3.1 \mathrm{~mm}$ thick and $2650 \mathrm{~mm}$ rotary-cut beech veneers. The veneer basic population consisted of thirty $2650 \mathrm{~mm}$ long (in grain direction) and 
$1320 \mathrm{~mm}$ wide veneer sheets of quality class E (EN 635-2 1995), provided by a Swiss producer (HESS \& Co AG). Subsequently to veneer conditioning in NC until constant mass, the veneer gross density $\rho_{\mathrm{N}}$ was taken, whereby $\rho_{\mathrm{N}}$ of each CLHS was calculated as average mean of the single veneer layers. To ensure a uniformly distributed forming pressure for the production of circular half-sections with small radii, a three-stage production process was developed using a fluid-filled fire hose for application of the forming pressure.

1. Veneer preparation: Veneers are wetted on their open side (peeling crack side) for preliminary forming of $3 \mathrm{~mm}$ thick veneers to a minimum radius of $30 \mathrm{~mm}$ perpendicular to the fibre direction. The fixed form, using perforated PVC tubes, is stored in NC for drying at least until constant mass of the veneers. Due to this wetting procedure, small veneer radii are generally produced without crushing the veneers.

2. Adhesive application: After veneer drying, adhesive is applied on the right side (side with closed peeling cracks, log periphery) of each veneer to bond the circu-

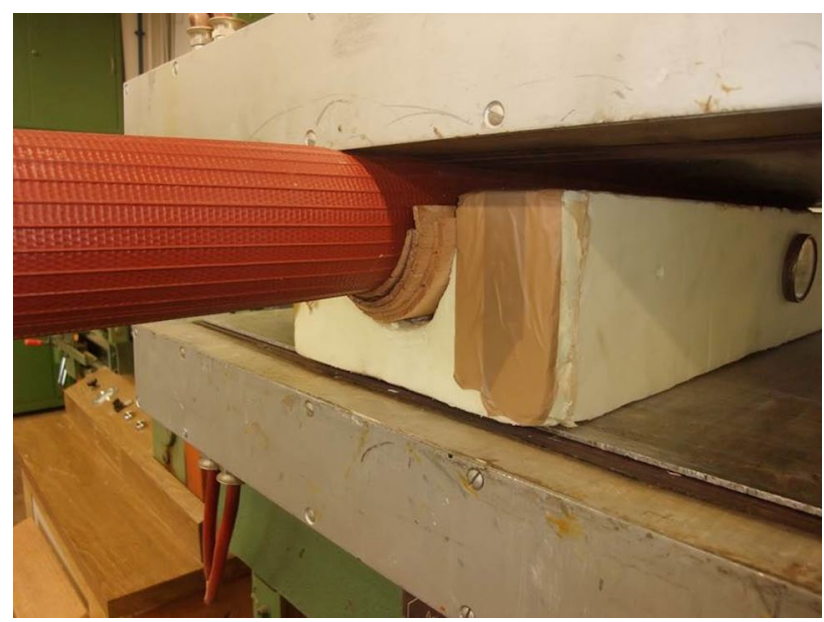

Fig. 4 Compression molding with radial press stress using an elastic fire hose and a circular press form lar half-sections, whereby the amount of resin is controlled by weighing.

\section{Bonding process of half sections}

For the production of half-sections, a system with a hard, circular outer form and an inner elastic form is used (Fig. 4). The outer hard form is made from steel and the inner elastic form consists of a $75 \mathrm{~mm}$ diameter fire hose with caps on both ends and connectors for compressed water. The use of an outer steel mould enabled the production of dimensionally consistent half-sections. Depending on the compressor unit and the bursting pressure of the fire hose, not more than 1.0 MPa radial forming pressure is applied. For the production of longer CLHS, as required for the use in reinforced soil walls $\left(\mathrm{L}_{\mathrm{N}}=0.6 \sim 1.0 \mathrm{H}_{\mathrm{S}}\right)$, a prototype press was developed.

The prototype press (Fig. 5) is designed in C-shape for a manual loading from the front side. The main frame consists of four $160 \mathrm{~mm}$ thick C-shaped CLT elements with an upper and lower pressure bar (HEB 160-S 235) placed in the recess of the CLT elements.

The steel-moulded rigid outer part in the form of a halfpipe is placed on the bottom height-adjustable pressure bar, which is lowered during the material loading. After placing the adhesive-wetted veneers in the rigid outer form (Fig. 4), the bottom pressure bar is raised until the fluidfilled fire hose makes contact with the veneers. A hydraulic inflation system connected to the end caps of the fire hose generates the final press force. After a curing time of at least $105 \mathrm{~min}$, the half-sections are removed and equalised in a planning unit. To reach a core temperature of the veneer layers of at least $30^{\circ} \mathrm{C}$, the fire hose is filled with water at $65{ }^{\circ} \mathrm{C}$. Additionally, 15 heating pads of 65 [W] capacity each are externally applied to the press dies in every single field (Fig. 5 right) and produce $65{ }^{\circ} \mathrm{C}$ surface temperature for the acceleration of the MUF adhesive curing process. Subsequently, the equalised half-sections are butt-jointed in a similar process and complete CLHS are formed (Fig. 6).
Fig. 5 Prototype press. Front view (left), detailed view of the press dies (right)
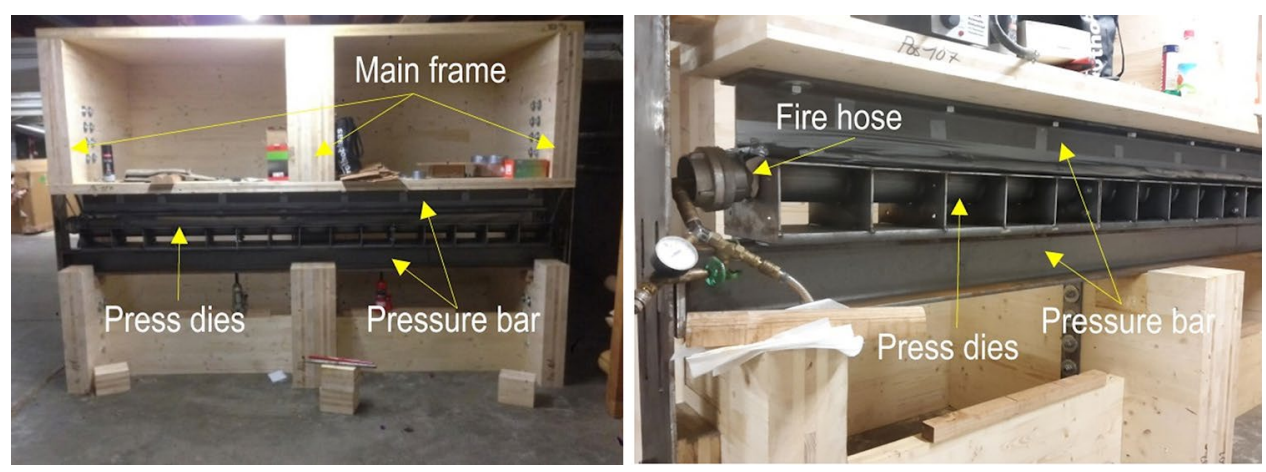


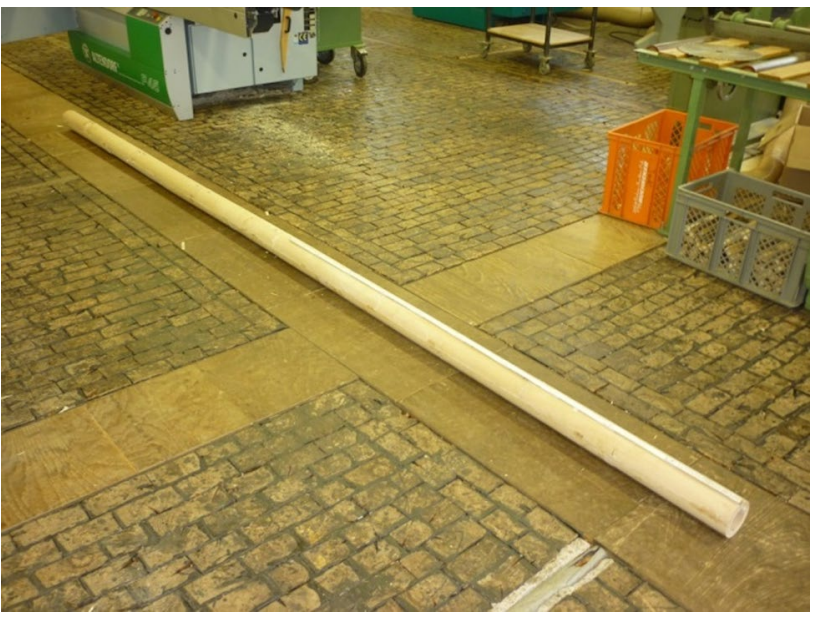

Fig. 6 CLHS prototype

\subsection{CHLS testing}

Specimen geometry and clamping construction (Fig. 7) was developed in several preliminary tests correlating the CLHS tensile loading capacity to the clamping system. For CLHS bonding (veneer surface bonding and butt-jointing), melamine formaldehyde resin (BASF Kauramin ${ }^{\circledR} 683$ with Kauramin ${ }^{\circledR} 688$ hardener) was used. Two additional $2 \mathrm{~mm}$ thick and $400 \mathrm{~mm}$ long veneers at the tube interior and six layers $1 \mathrm{~mm}$ thick and $600 \mathrm{~mm}$ long carbon fibre (FRP) reinforcement (one layer axially and five layers tangentially oriented) prevented the clamping section from splitting due to the high tangential forces caused by the wedge clamping system (Fig. 8).

Besides four CLHS for clamping system verification and estimation of the maximum load $F_{\text {max,est }}$, a further 20 CLHS (nominal outer diameter $d_{t}=100 \mathrm{~mm}$ and nominal inner diameter $\mathrm{d}_{\mathrm{i}}=75 \mathrm{~mm}$ ) with $1250 \mathrm{~mm}$ free testing length

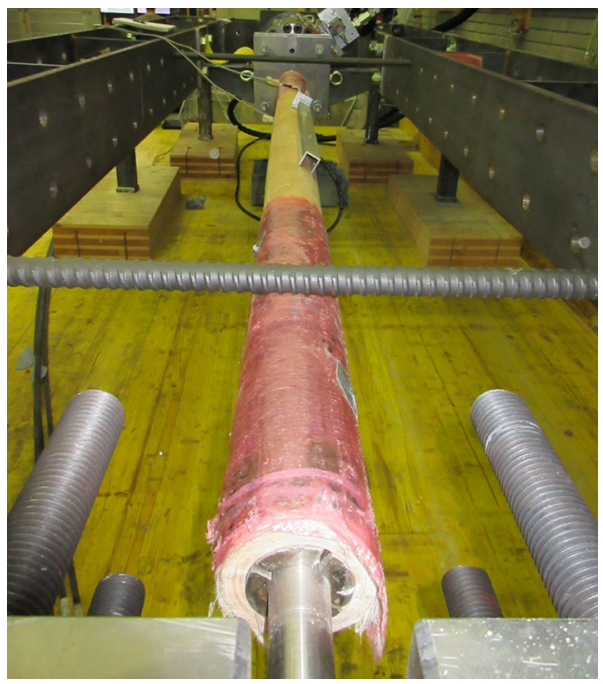

Fig. 8 Clamping detail

between the FRP reinforcement were produced. Half of the produced samples were used for tensile testing of continuous CLHS without longitudinal joints (batch "CLHS"). The rest was used for the investigation of finger-jointed CLHS with a longitudinal joint. In total, ten continuous and ten longitudinally jointed CLHS were produced, whereby five were half-section jointed and five had a complete crosssectional joint. One additionally manufactured half section, produced from randomly chosen veneer sheets of the same basic population, was cut into strips and formed to 48 small bone-shaped specimens (batch "Bone"). This geometry is similar to the on described in Hirschmüller et al. (2016, $2018 \mathrm{a}, \mathrm{b})$ and was used for tension strength testing after NC conditioning. The full-sized CLHS tensile tests (Fig. 9) were performed according to EN 408 (2012) at Technische Versuchs- und Forschungsanstalt of Universität Innsbruck in a specially developed steel frame using a $1 \mathrm{MN}$ servo
Fig. 7 Longitudinal (axial) section of the full-sized CLHS test setup including the wedge clamping construction

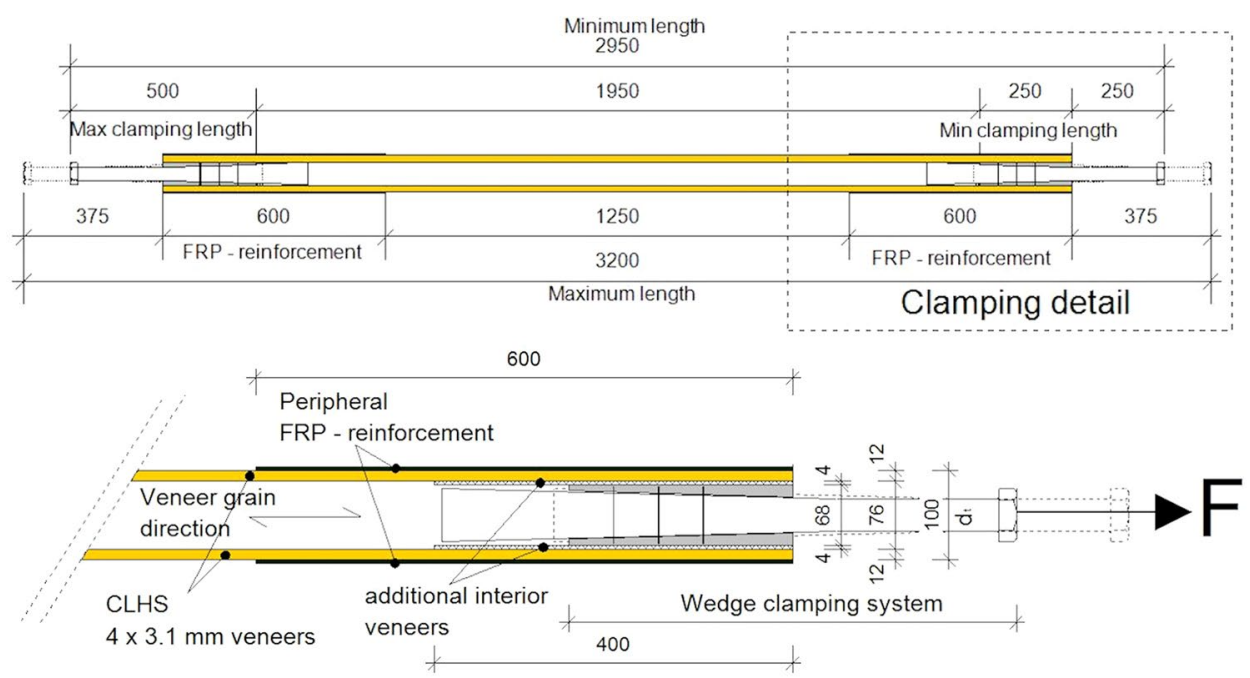




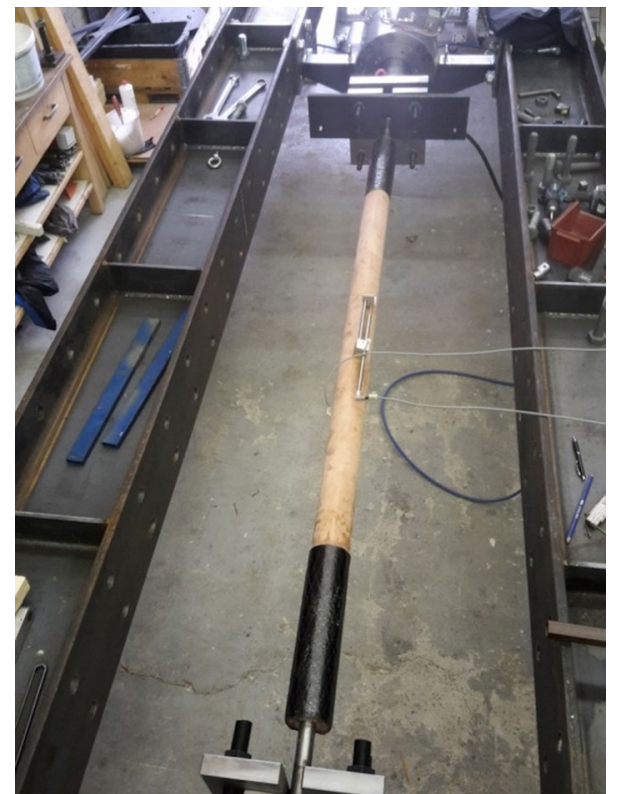

Fig. 9 Test setup of a full-sized CLHS

hydraulic testing machine. The stroke-controlled load was applied with a constant rate of piston displacement of $2 \mathrm{~mm} / \mathrm{s}$, leading to testing cycles of $10 \mathrm{~min}$ per test. Thereby, ultimate loads up to $326(\mathrm{kN})$ were achieved. The application of higher displacement rates was not possible due to rough jerks occurring within the wedge clamping system. As the load from the piston to the CLHS was transferred by friction between the inner CLHS surface and the clamping jaws, a large displacement between the inner expansion shaft and the clamping jaws was necessary to generate the required force perpendicular to both surfaces (Figs. 7, 8), which resulted in a machine stroke up to $250 \mathrm{~mm}$ during loading, caused by slipping between the wedge clamping system's cone and chucks. Three continuous samples without joints (batch "CLHS") had to be adjusted during the tests as the maximum machine stroke of $250 \mathrm{~mm}$ was reached. The tests were conducted in non-conditioned environment at a temperature of about $20{ }^{\circ} \mathrm{C}$. The longitudinal strain was measured at the free testing length's mid-section using two symmetrically installed linear inductive displacement sensors with a measuring length of $500 \mathrm{~mm}$. The displacement sensors were manually removed after a loading level of approximately $50 \% F_{\text {max,est }}$. Each sensor placed upon a half section was positioned perpendicular to the butt joint for the evaluation of sample curvature during testing, due to possibly different stiffnesses between the two half sections.

\subsection{CLHS finger jointing}

The finger joints (FJ) were manufactured at a local glulam producer (Grossman Bau GmbH\&CoKG, Rosenheim,

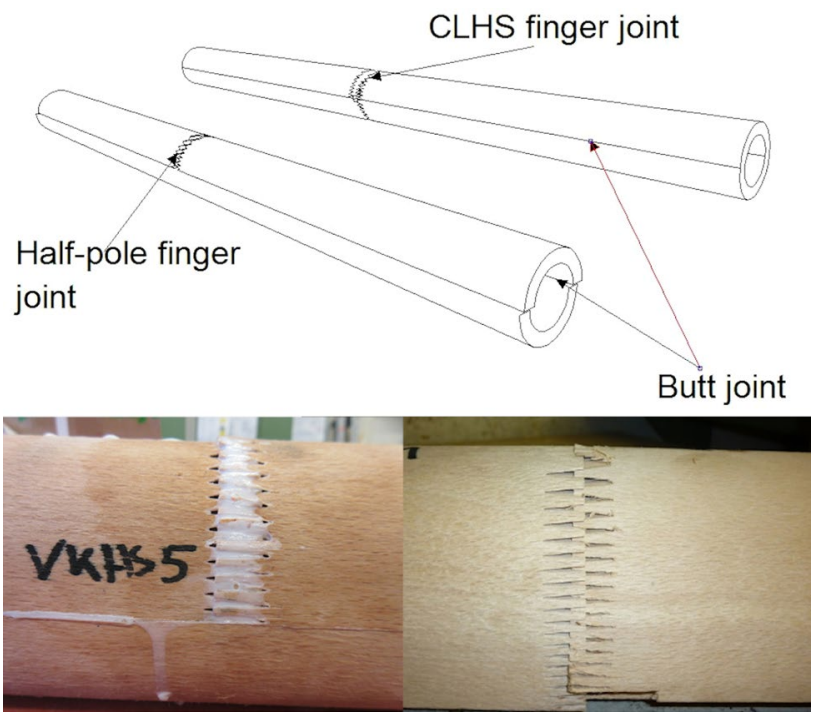

Fig. 10 Half-pole finger joint HFJ (left) and finger jointing of the complete CLHS cross-section FFJ (right)

Germany) using a common $15 \mathrm{~mm}$ finger-jointing profile (I 15/3.8; pitch $=3.8 \mathrm{~mm}$, tip width $0.42 \mathrm{~mm}, 15 \mathrm{~mm}$ finger length and cross-section reduction factor $\nu=0.11$ ) at a pressure level of $11 \mathrm{MPa}$. The adhesive used was of melamine type (BASF Kauramin ${ }^{\circledR} 683$ with Kauramin ${ }^{\circledR}$ 688 hardener) and applied manually no later than $6 \mathrm{~h}$ after cutting the fingers. For the jointing of circular geometries, a special clamping model was developed to avoid CLHS crushing during the clamping process. Two different FJ arrangements were produced, one to mimic a staggered arrangement of FJ within the CLHS section (batch "HFJ") and one with fully finger-jointed CLHS across the complete CLHS cross-section (batch "FFJ"). For the production of HFJ series, in a first step, $2500 \mathrm{~mm}$ long half-poles were produced, cut into two pieces of equal length, and subsequently jointed again to a half-pole consisting of one finger joint in the mid-section of the free testing length.

Thereby, the finger edges were oriented parallel to the longitudinal CLHS butt joint. After $1 \mathrm{~h}$ of adhesive curing, the finger-jointed half-poles were equalised in a planning unit and butt-jointed to continuous half-poles to form a complete CLHS (Fig. 10).

FFJ series was produced similarly to the HFJ series by cutting the CLHS in half, and the two halves were connected back together with finger jointing of the complete cross-section.

After CLHS production and clamping section reinforcement, the finger-jointed specimens were conditioned for 2 months at NC prior to testing. One FFJ member failed during the installation, thus, in total, a number $\mathrm{n}$ of ten CLHS, five HFJ and four FFJ was tested. 
The tensile strength $f_{t}$ of the samples was calculated using Eq. (1):

$$
f_{t}=\frac{4 \cdot F_{\max }}{\pi \cdot\left(d_{t}^{2}-d_{i}^{2}\right)}
$$

where $\mathrm{F}_{\text {max }}$ : maximum load at failure, $\mathrm{d}_{\mathrm{t}}$ : nominal outer CLHS diameter, $\mathrm{d}_{\mathrm{i}}$ : nominal inner CLHS diameter.

The modulus of elasticity MOE was determined by an averaged strain measurement of the displacement sensors placed in the mid-section of the sample with a linear regression analysis of the stress-strain diagram, with a correlation coefficient of $\mathrm{R}>0.99$ (Eq. 2).

$M O E=\frac{4 \cdot \Delta F}{\pi \cdot\left(d_{t}^{2}-d_{i}^{2}\right) \cdot \Delta \varepsilon}$

Fig. 11 Stress-strain diagram of finger-jointed structural sized members (FFJ/HFJ) and continuous members without joints (CLHS); strain calculated as average between sensor 1 and sensor 2 where $\Delta \mathrm{F}$ : load increase within the linear range of the stress-strain curve, $\Delta \varepsilon$ : strain increase within the linear range of the stress-strain curve.

\section{Results and discussion}

In a first step, the stress-strain (Fig. 11) and the force-sensor displacement diagrams (Fig. 12) were evaluated for differences in sensor elongation. A slight curvature during testing was expected due to the reduced cross-section area of the jointed half section $(\nu=0.11)$ resulting in a differential axial stiffness between the components. However, no significant difference in sample curvature between the three evaluated structural-sized series could be found. The maximum observed differential strain of $\Delta \varepsilon=0.9 \%$ in batch HFJ was similar to the corresponding series FFJ and CLHS, and

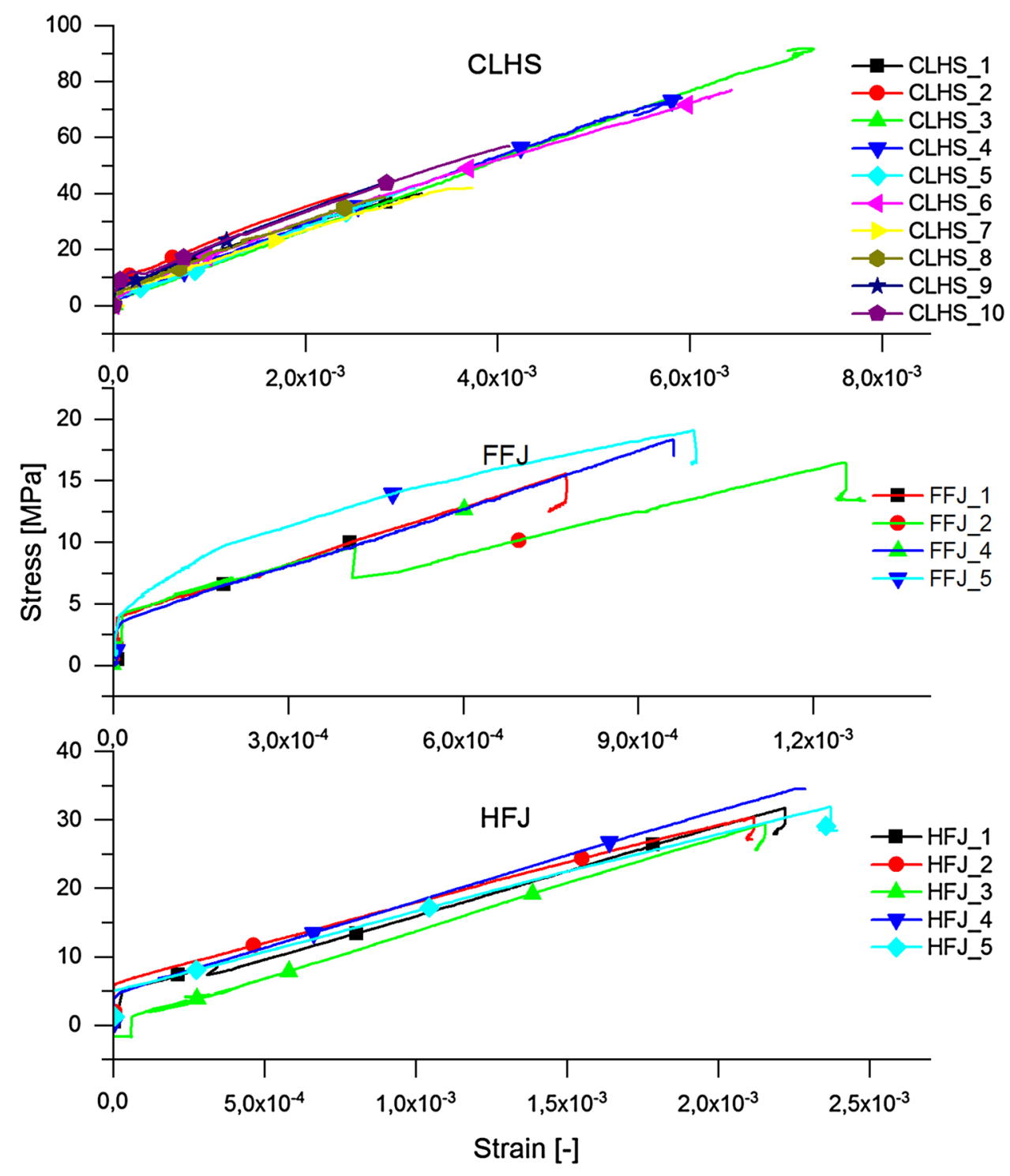


Fig. 12 Force-sensor displacement (elongation is plotted with negative values) diagram of FFJ fully finger-jointed CLHS (bottom) and members with finger jointed half sections HFJ (top); solid line displacement sensor 1 , dotted line displacement sensor 2

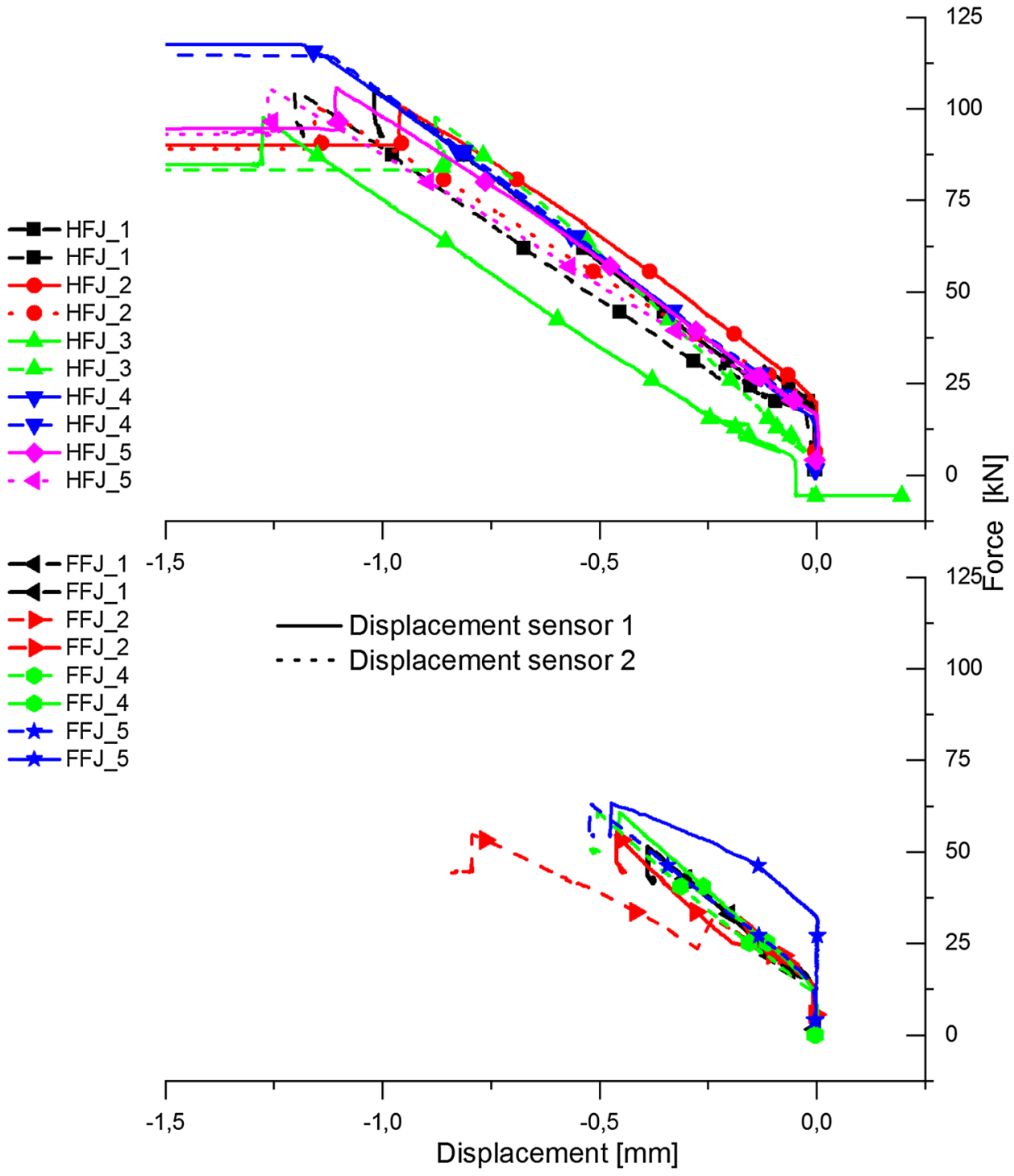

therefore, the curvature was rather determined by different material stiffnesses of the butt-jointed half-poles. For simplification, the tensile results were applied to the full CLHS cross-section, neglecting the cross-section reduction factor $(\nu=0.11)$ of the finger joints.

Due to the high-grade veneers being almost free from defects, the tensile results show a high characteristic tensile strength $\mathrm{f}_{\mathrm{t}, \mathrm{k}}$ of the structural-sized CLHS sections without a longitudinal joint (Table 1 and Fig. 13). Hereby, moderate scattering values (coefficient of variation $\mathrm{COV}=10 \%$ ) were given. Nevertheless, the results obtained from the control batch "Bone", consisting of $n=48$ small-sized specimens free from defects are in accordance with published values of beech single veneer tensile properties (Buchelt and Pfriem 2011).

A comparison of the normal or lognormal distributed mean strengths $\bar{x}$ and median strengths $\tilde{\mathrm{x}}$ of full fingerjointed members FFJ and sectional-jointed members HFJ by a t-test on two independent samples (including a Welch correction factor in case of unequal variances) at a level of significance of $\alpha=0.05$ revealed no significant difference in means between both jointing arrangements. However, the low test power $(\mathrm{P}=0.11)$ obtained allows no statistically sufficient assessment of the results (hypothetical sample size $\mathrm{n}>80$ for a test power $\mathrm{P} \geq 0.7$, as required by Sachs 1993). This has also been reflected in a low characteristic tensile strength of batch FFJ $\left(f_{t, k}=27 \mathrm{MPa}\right)$ due to the low number of tested samples $(n=4)$, in combination with a remarkable standard deviation $(\mathrm{SD}=10.30 \mathrm{MPa})$.

Similar to the findings on small specimens free from defects, presented by Hirschmüller et al. (2018b), only a poor correlation was found between the common strength grading criteria MOE and $\mathrm{f}_{t}$, and almost no correlation between $\rho_{N}$ and $\mathrm{f}_{\mathrm{t}}$ and MOE respectively (Fig. 14). These findings emphasise the need for improved grading parameters for beech LVL, including a reliable determination 
Table 1 Tensile test results of structural sized series CLHS, HFJ and FFJ, compared to results of small, clear specimens (Bone) and literature values LIT 1 (Buchelt and Pfriem 2011), LIT 2 (Pollmeier Massivholz GmbH\&CoKG 2018)

\begin{tabular}{|c|c|c|c|c|c|c|c|c|c|}
\hline \multirow[t]{2}{*}{ Group } & \multicolumn{9}{|c|}{ Parameter } \\
\hline & Test & $\mathrm{n}$ & $\overline{\mathrm{x}}(\mathrm{MPa})$ & $\mathrm{SD}(\mathrm{MPa})$ & $\operatorname{COV}(\%)$ & $\tilde{\mathrm{x}}(\mathrm{MPa})$ & $\mathrm{f}_{\mathrm{t}, \mathrm{k}}(\mathrm{MPa})$ & $\mathrm{u}_{\mathrm{gl}}(\%)$ & $\rho_{\mathrm{N}}\left(\mathrm{kg} / \mathrm{m}^{3}\right)$ \\
\hline \multirow[t]{2}{*}{ CLHS } & $f_{t}$ & 10 & 86.77 & 9.05 & 10 & 86.04 & 69 & 11.8 & 677 \\
\hline & MOE & 10 & 12,393 & 1053 & 8 & 12,513 & - & 11.8 & \\
\hline \multirow[t]{2}{*}{ HFJ } & $f_{t}$ & 5 & 54.82 & 6.76 & 12 & 56.79 & 39 & 11.4 & 649 \\
\hline & MOE & 5 & 12,669 & 994 & 14 & 13,016 & - & 11.4 & \\
\hline \multirow[t]{2}{*}{ FFJ } & $f_{t}$ & 4 & 49.80 & 10.30 & 21 & 51.83 & 27 & 11.5 & 719 \\
\hline & MOE & 4 & 13,677 & 1905 & 8 & 13,938 & - & 11.5 & \\
\hline \multirow[t]{2}{*}{ Bone } & $f_{t}$ & 48 & 98.39 & 16.21 & 16 & 98.20 & 71 & 11.1 & - \\
\hline & MOE & 48 & 12,692 & 770 & 6 & 12,832 & - & 11.1 & \\
\hline \multirow[t]{2}{*}{ LIT 1} & $f_{t}$ & 80 & 99.6 & 24.9 & 25 & - & - & - & - \\
\hline & $M O E$ & 80 & 12,963 & 1687 & 13 & - & - & - & \\
\hline \multirow[t]{2}{*}{ LIT 2} & $f_{t}$ & - & - & - & - & - & 60 & - & 800 \\
\hline & $M O E$ & - & 16,800 & - & - & - & 14,900 & - & \\
\hline
\end{tabular}

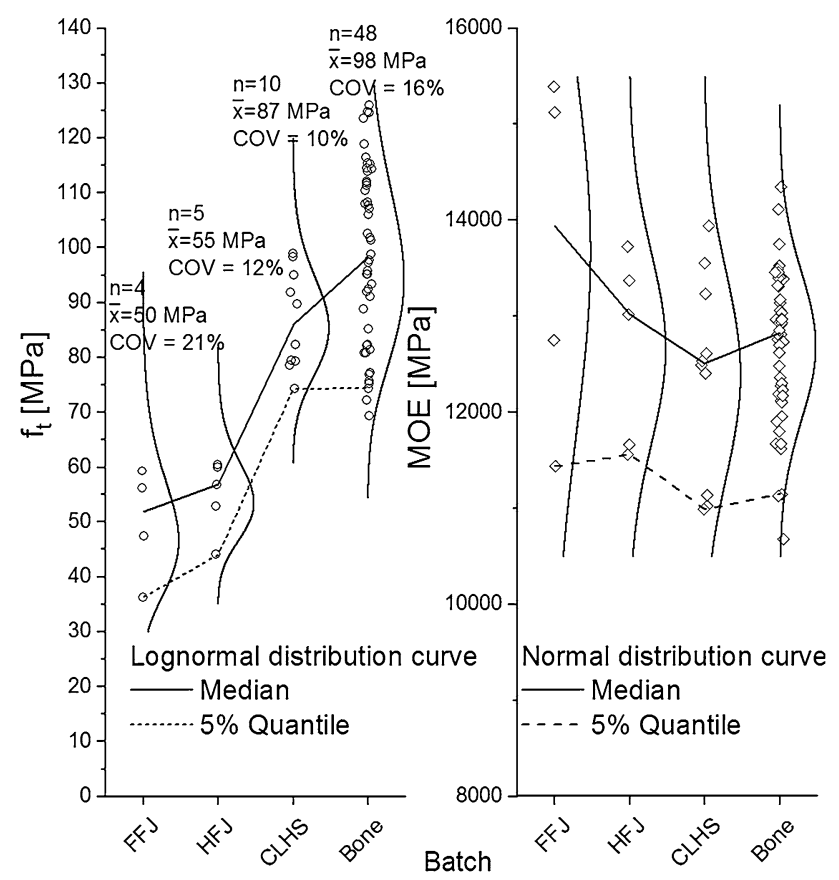

Fig. 13: Scatter diagram of $f_{t}$ (left) and MOE (right), comparing series FFJ, HFJ, CLHS and Bone

of the veneer grain deviation as extensively described in Ravenshorst (2015). The failure mechanism of jointed samples was determined by the reduced cross-section at the joint as expected. All 19 samples failed within the free testing length (Fig. 15 top). In all HFJ samples, cracks initially occurred at the fingertip, leading to a brittle tensile failure of the jointed half section. After following a crack path along the butt joint, the complementary half section (without joint) failed at the weakest link in a short-fibred fracture pattern typical of beech (Fig. 15 bottom left).
All FFJ samples failed at the finger joint, revealing a tensile failure at the fingertip or a shear failure at the finger sides, but always with fracture in the timber member (Fig. 15 bottom right). Just one member already failed during the clamping work due to an insufficient bond (FFJ_3) and had to be removed from further evaluation as no results could be obtained.

Despite a larger cross-section reduction in full fingerjointed sections, the difference in mean strength between FFJ sections (43\% strength reduction compared to reference CLHS) and HFJ sections (37\% strength reduction) is marginal, but still has to be improved and evaluated in further research. The results follow previous research on finger-jointed beech wood lamellas and beech glued laminated timber published in Aicher et al. (2001), Volkmer et al. (2017) and Ehrhart et al. (2018). The strength of the structural members is governed by the strength of the fingerjointed lamellas. In half of the FFJ samples, a shear failure on the finger sides was observed, resulting in lower strength, larger scattering and thus a low characteristic strength. In summary, based on the data presented it can be stated that (1) even at a level of significance $\alpha=1 \%$ neither normal and lognormal nor Weibull distribution of $f_{t}$ and MOE in batch CLHS could be rejected, (2) no correlation was found between $\mathrm{MOE}\left(\mathrm{f}_{\mathrm{t}}\right)$ and $\rho_{N}$ and (3) MOE and $\mathrm{f}_{\mathrm{t}}$ are poor positively correlated.

\section{Conclusion}

NC conditioned beech CLHS achieve superior tensile properties, independent of the circular profile geometry. Finger jointing as an efficient and industrially well-established method of connecting plane timber members is also applicable to circular, layered veneer structures, although the abrasive bond lines require cutter head modifications to achieve 
Fig. 14 Correlation between $f_{t}$ and MOE (left) and $\mathrm{f}_{\mathrm{t}}$ and $\rho_{N}$ (center) and MOE and $\rho_{N}$ (right) of batch "CLHS"

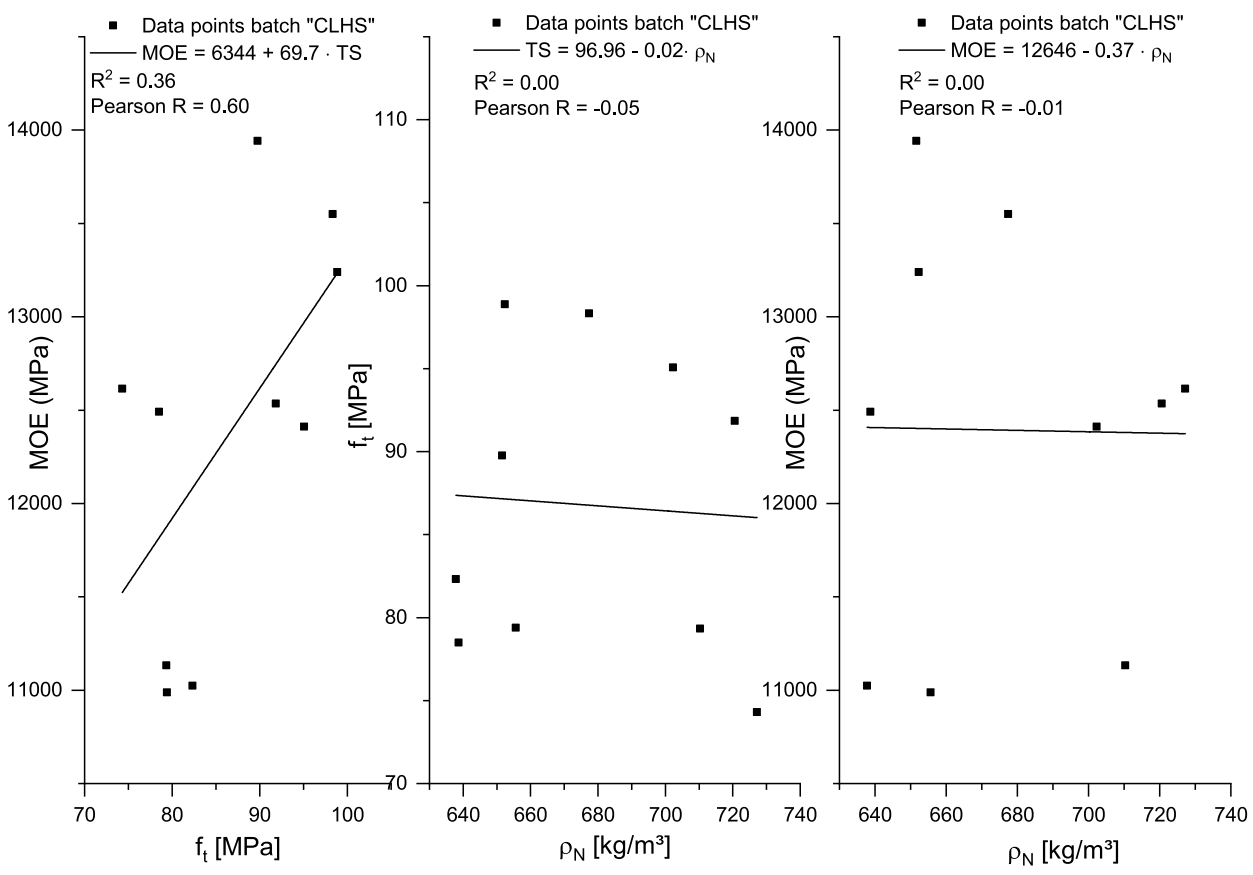

a service life similar to applications to solid timber elements. For the use of the CLHS in state of the art soil nail constructions, the strength reduction caused by finger-jointing to endless members has to be investigated more in-depth, as the insitu material strength of the structural beech wood poles is strongly reduced by the high subsoil wood moisture content and the permanent cement contact. Although finger jointing is a promising alternative to staggered veneers for the production of circular and structural sized endless CLHS, further investigations are necessary. In particular, investigations into the relation between finger-jointing strength

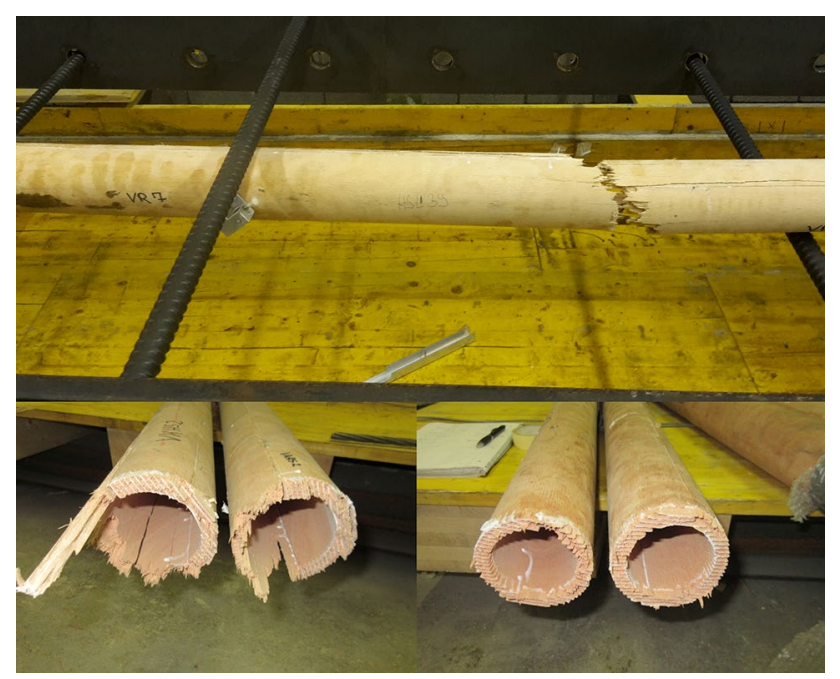

Fig. 15 Exemplary fracture patterns of CLHS (top), HFJ series (bottom left) and FFJ series (bottom right) development and the material strength of unjointed members considering those strong climatic conditions in combination with high moisture contents of the material are necessary and will be part of future projects. Additionally, improvements in the bonding process and the adhesive type of the finger joints are possible. For the provision of comprehensive design strength values larger test series are necessary.

Acknowledgements Open Access funding provided by Projekt DEAL. This work was supported by the Federal Ministry of Education and Research under Grant 13FH022IX4.

Open Access This article is licensed under a Creative Commons Attribution 4.0 International License, which permits use, sharing, adaptation, distribution and reproduction in any medium or format, as long as you give appropriate credit to the original author(s) and the source, provide a link to the Creative Commons licence, and indicate if changes were made. The images or other third party material in this article are included in the article's Creative Commons licence, unless indicated otherwise in a credit line to the material. If material is not included in the article's Creative Commons licence and your intended use is not permitted by statutory regulation or exceeds the permitted use, you will need to obtain permission directly from the copyright holder. To view a copy of this licence, visit http://creativecommons.org/licenses/by/4.0/.

\section{References}

Aicher S (ed) (2001) Joints in timber structures. Proceedings of the international RILEM symposium]; Stuttgart, Germany, 12-14 September 2001. RILEM proceedings PRO, vol 22. RILEM Publications, Cachan, France

Aicher S, Höfflin L, Behrens W (2001) A study on tension strength of finger joints in beech wood laminations. Otto Graf J 12:169-186 
Biblis EJ, Carino H (1993) Factors influencing the flexural properties of finger-jointed southern ping LVL. For Prod J 43(1):41-46

Buchelt B, Pfriem A (2011) Influence of wood specimen thickness on its mechanical properties by tensile testing: solid wood versus veneer. Holzforschung 65:249-252

Ehrhart T, Steiger R, Palma P, Frangi A (2018) Mechanical properties of European beech glued laminated timber. In: International council for research and innovation in building and construction (ed) Working commission W18-Timber structures, 51-12-04. Timber Scientific Publishing, KIT Holzbau und Baukonstruktionen, Karlsruhe

EN 15497 (2014) Structural finger jointed solid timber-performance requirements and minimum production requirements. European Committee for Standardization, Brussels

EN 408 (2012) Timber structures-structural timber and glued laminated timber-determination of some physical and mechanical properties. European Committee for Standardization, Brussels

EN 635-2 (1995) Plywood—classification by surface appearance-part 2: hardwood. European Committee for Standardization, Brussels

Gäßler G (1987) Vernagelte Geländesprünge-Tragverhalten und Standsicherheit. (Nailed slopes-load-bearing behaviour and structural stability). Ph.D.-thesis, Universität Fridericiana Karlsruhe

Gäßler G, Gudehus G (1981) Soil nailing - some aspects of a new technique, Proceedings of tenth international conference on soil mechanics and foundation engineering, vol 3, Session 12, Stockholm, pp 665-670

Gilbert BP, Underhill ID, Fernando D, Bailleres H (2017) Structural solutions to produce long timber veneer based composite hollow sections. Constr Build Mater 139:81-92. https://doi.org/10.1016/j. conbuildmat.2017.02.046

Hara Y, Kawai S, Sasaki H (1994) Manufacture and mechanical properties of cylindrical laminated veneer lumber. Wood Res 81:28-30

Hata T, Umemura K, Yamauchi H, Nakayama A, Kawai S, Sasaki H (2001) Design and pilot production of a "spiral-winder" for the manufacture of cylindrical laminated veneer lumber. J Wood Sci 47(2):115-123. https://doi.org/10.1007/BF00780559

Hirschmüller S (2019) Beech circular hollow laminated veneer lumber sections for temporary soil nailing applications. Ph.D. thesis, Graz University of Technology

Hirschmüller S, Marte R, Pravida J (2016) Laminated veneer lumber poles for temporary soil nailing-investigation of material properties. In: Eberhardsteiner J, Winter W, Fadai A, Pöll M (eds) WCTE 2016. Proceedings of the World Conference on Timber Engineering. Vienna University of Technology, Vienna
Hirschmüller S, Marte R, Pravida J, Flach M (2018a) Inhibited wood degradation of cement-coated beech Laminated Veneer Lumber (LVL) for temporary in-ground applications. Eur J Wood Prod 76(5):1483-1494. https://doi.org/10.1007/s00107-018-1325-9

Hirschmüller S, Pravida J, Marte R, Flach M (2018b) Long-term material properties of circular hollow laminated veneer lumber sections under water saturation and cement alkaline attack. Wood Mat Sci Eng 81(4):1-15. https://doi.org/10.1080/17480272.2018.1434830

Pollmeier Massivholz GmbH\&CoKG (2018) BauBuche Beech laminated veneer lumber. Characteristic static strength values and dimensioning table, Creuzburg

Project National Clouterre (1991) Recommandation Clouterre 1991. Pour la conception, le calcul, l'exécution et le contrôle des soutènements réalisés par clouage des sols. (Recommendations CLOUTERRE 1991. Soil Nailing Recommendations-1991 for Designing, Calculating, Constructing and Inspecting Earth Support Systems Using Soil Nailing (English Translation, July 1993)). Presses de l'Ecole Nationale de Ponts et Chausses, Paris

Ravenshorst GJP (2015) Species independent strength grading of structural timber. Ph.D. thesis, Delft University of Technology

RVS 09.01.41 (2013) Tunnelbau, offene Bauweise (Tunneling, Design Guide Lines, Cut and Cover Tunnel). Federal Ministry for Transport Innovation and Technology, Vienna

Sachs L (1993) Statistische Methoden; Planung und Auswertung. (Statistical methods; planning and evaluation), 7th revised. Springer, Berlin

Srinivasan N, Jayaraman K, Bhattacharyya D (2008) Profile production in multi-veneer sheets by continuous roll forming. Holzforschung 62:453-460

Volkmer T, Lehman M, Clerc G (2017): Brettschichtholz aus Buche: Keilzinkenverbindung und Flächenverklebung. (Glued laminated timber made of beech wood: Finger joints and surface bonding). In: Forum Holzbau (Hg.): 23th international wood construction conference (IHF). Garmisch, Germany, 06.-08.12.2017

Youngquist JA, Laufenberg TL, Bryant BS (1984) End jointing of laminated veneer lumber for structural use. For Prod J 34(11-1):25-32

Publisher's Note Springer Nature remains neutral with regard to jurisdictional claims in published maps and institutional affiliations. 